\title{
ENSAYOS PRELIMINARES DE GERMINACIÓN EN Puya raimondii Harms (BROMEI_IACEAE)
}

\author{
PRELIMINARY GERMINATION TRIALS IN Puya raimondii Harms \\ (BROMELIACEAE)
}

\author{
Mery L. Suni' ${ }^{1}$ Asunción Cano $^{2}$ y Giovana Vadillo ${ }^{1}$
}

\section{RESUMEN}

Puya raimondii Harms es una especie endémica de la zona altoandina de Perú y Bolivia, cuyas poblaciones y área de distribución se están reduciendo. Con el objetivo de contribuir al conocimiento de los mecanismos de propagación de la especie se realizaron estudios del efecto de la iluminación y estratificación en la germinación de sus semillas. Éstas se colectaron en el rodal de $P$. raimondii de Huashta Cruz (Pueblo Libre, Áncash) en diciembre de 1999 y fueron almacenadas bajo condiciones de laboratorio en Lima, Perú, hasta el momento de los ensayos. Las semillas fueron desinfectadas con hipoclorito de sodio $2,6 \%$ y la germinación se realizó en placas petri con agua destilada estéril durante el año 2000. Los resultados preliminares muestran que las semillas de $P$. raimondii tienen altos valores de porcentaje e índice de velocidad de germinación al ser iluminadas. Efecto semejante tuvo estratificarlas por dos meses a $11^{\circ} \mathrm{C}$ o incrementar el tiempo de almacenamiento hasta 8 meses pero resultó negativo aplicar los dos tratamientos a la vez. Se plantea que los altos contenidos de humedad de la semilla, temperatura de almacenamiento así como temperatura de germinación afectan negativamente los valores de germinación.

Palabras slave: Puya raimondii, germinación, Bromeliaceae, semilla, conservación.

\section{ABSTRACT}

Puya raimondii Harms is an endemic especie of the highlands of 'Peru and Bolivia, whose population and area of distribution are being reduced. Aiming at contributing to the knowledge of the mechanisms of propagation of this species, a study of the effects of the illumination and stratification on the germination of the seed was carried out. The seed was collected in the rodal of Puya raimondii in Huashta Cruz (Pueblo Libre, Ancash) in December 1999 and were stored under laboratory conditions in Lima until the tests. The seeds were desinfected with sodium hipochloride $2,6 \%$ and for the germination test seeds were placed in petri dishes wilh distilled and sterilized water during 2000. The preliminary results show that the seed of Puya raimondii has a high percentage and velocity of germination when exposed to light. A similar effect was achieved by stratifying them for two months at $11^{\circ} \mathrm{C}$ or by increasing time of storage to 8 months, but germination dropped upon applying both processes simultaneously. We hypothesize that the high seed moisture content and high temperature during storage and germination affect germination success negatively.

Key words: Puya raimondii, germination, Bromeliaceae, seed, conservation.

\section{INTRODUCCIÓN}

Puya raimondii Harms, "cuncosh", "santón", "titanca" o "cara" es una especie endémica de los Andes. Es un elemento característico y sobresaliente de la flora del Perú debido a su belleza paisajista, gran tamaño y

- Laboratorio de Fisiología Vegetal. Facultad de Ciencias Biológicas. UNMSM. Apartado 11-0058, Lima 11. E-mail: d190053@unmsm.edu.pe

${ }^{2}$ Museo de Historia Natural. UNMSM. Apartado

14-0434. E-mail: d190084@unmsm.edu.pe adaptación a ambientes extremos, pero cuya población está siendo amenazada por factores humanos (quema y tala) y naturales (plagas y enfermedades). A esto se suma el desconocimiento del único medio de propagación que esta especie presenta, sus semillas, cuya producción se relaciona con el término de la vida del individuo, estimado a los 40 a 100 años de edad (Hartmann, 1981 y Rivera, 1985). Si bien esta planta produce de 6 a 12 millones de semillas por individuo (Rivera, 
Cuadro 1. Tratamientos aplicados en el primer y segundo experimento.

\begin{tabular}{ccccc}
\hline Tratamiento & Iluminación & Estratificación & $\begin{array}{c}\text { Temperatura- } \\
\text { estratificación }\left({ }^{\circ} \mathrm{C}\right)\end{array}$ & $\begin{array}{c}\text { Período- } \\
\text { estratificación (días) }\end{array}$ \\
\hline 1 & + & - & - & - \\
2 & + & + & 7 & 30 \\
3 & + & + & 11 & 30 \\
4 & + & + & 7 & 60 \\
5 & + & + & 11 & 60 \\
6 & - & - & - & - \\
7 & - & + & 7 & 30 \\
8 & - & + & 11 & 30 \\
\hline
\end{tabular}

1985 y Cano et al., 2000) estas aparentemente no alcanzan exitosamente otras fases de su desarrollo para dar lugar a nuevos individuos. De allí que el estudio de los factores que regulan la germinación y el establecimiento de las plántulas contribuirá al entendimiento de la biología de $P$. raimondii, y coadyuvará para la conservación de esta especie.

El escaso conocimiento que se tiene de los factores que determinan la germinación de $P$. raimondii es contradictorio. Lo que se conoce se refiere al tiempo de viabilidad de sus semillas; así Hartmann (1981) señala que son meses mientras que Rivera (1985) indica años. También se menciona que el tiempo para el inicio de la geminación es de 16 días según De la Cruz (2000) y otros 32 días según Rivera (1985). Ninguno de estos trabajos han sido hechos exclusivamente para estudiar la germinación de las semillas de esta especie.

En general, se sabe que muchas especies de Bromeliáceas requieren de luz para que sus semillas germinen (Downs, 1956 y Downs y Piringer, 1958, citados por Mercier y Guerreiro, 1990). Además, siendo que $P$. raimondii se desarrolla a elevadas altitudes en donde las plantas se ven sometidas diariamente a oscilaciones fuertes de temperatura con una mínima próxima a cero, es posible que sus semillas requieran pasar por bajas temperaturas antes de que germinen a fin de superar la dormancia (Mackay, 1972). Por ello el estudio de las semillas de $P$. raimondii se ha iniciado probando el efecto de la luz y el acondicionamiento a baja temperatura (estra- tificación) en la germinación. En este trabajo se reporta los resultados preliminares obtenidos al evaluar estos factores a fin de contribuir al conocimiento de los mecanismos de propagación de la planta y sentar las 'ases de su conservación.

\section{MATERIALES Y MÉTODOS}

Se usó semillas de $P$. raimondii de frutos colectados el 5 diciembre de 1999 en Huashta

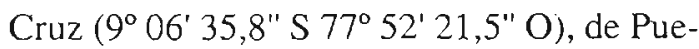
blo Libre, Huaylas, Áncash. Estas semillas fueron resultado de la fructificación del año anterior, las cuales fueron mantenidas a condiciones de laboratorio antes del primer ensayo (3,5 meses). Para el segundo ensayo en estas mismas condiciones (5,7 meses) luego almacenadas por dos meses y medio en refrigeración $\left(7^{\circ} \mathrm{C}\right.$, estratificación). Las semillas fueron desinfectadas con solución de hipoclorito de sodio $2,6 \%$ durante 10 minutos y la germinación se evaluó poniendo aproximadamente 40 semillas sobre papel filtro dentro de placas petri humedecidas con agua destilada estériles, lo cual asimismo nos permitió estimar su viabilidad.

Los factores evaluados fueron iluminación (con o sin ella), estratificación (con o sin ella), temperatura de estratificación $\left(7 \mathrm{u} 11^{\circ} \mathrm{C}\right)$ y período de estratificación (30 días o 60 días). Ver Tabla 1.

La iluminación correspondió a la natural en Lima y el tratamiento sin iluminación (oscuridad) se logró cubriendo las placas com- 
Cuadro 2. Número de semillas germinadas, porcentaje de germinación e índice de velocidad de germinación (IVG) obtenidos para los tratamientos aplicados a semillas de $P$. raimondii en el primer y segundo ensayos

\begin{tabular}{|c|c|c|c|c|c|c|c|c|}
\hline \multirow{3}{*}{$\begin{array}{c}\text { Estratfic. }\left({ }^{\circ} \mathrm{C} / \mathrm{d}\right) \\
\text { Tratamiento }\end{array}$} & \multicolumn{5}{|c|}{ Luz } & \multicolumn{3}{|c|}{ Oscuridad } \\
\hline & $\mathbf{L}$ & $7 / 30$ & $11 / 30$ & $7 / 60$ & $11 / 60$ & $\mathrm{O}$ & $7 / 30$ & $11 / 30$ \\
\hline & 1 & 2 & 3 & 4 & 5 & 6 & 7 & 8 \\
\hline \multirow[b]{2}{*}{$\begin{array}{l}\text { Promedio } \\
\text { sem. germs. / placa }\end{array}$} & \multicolumn{8}{|c|}{ Primer Ensayo } \\
\hline & $10 / 40$ & $5 / 10$ & - & $11,5 / 20$ & $15 / 20$ & $1,5 / 40$ & 0 & $2 / 10$ \\
\hline$\%$ germinac. & 25 & 50 & - & 57,5 & 75 & 3,75 & 0 & 20 \\
\hline \multirow[t]{2}{*}{ IVG } & 0,26 & 0,07 & - & 0,37 & 0,48 & 0,02 & 0 & 0,05 \\
\hline & \multicolumn{8}{|c|}{ Segundo Ensayo } \\
\hline N. ${ }^{\circ}$ sem. germs. /placa & $16,5 / 40$ & $6,5 / 40$ & $14 / 40$ & $3 / 35$ & $1 / 35$ & $2,5 / 35$ & - & 0 \\
\hline \% germinac. & 41 & 16,3 & 35 & 8,6 & 2,86 & 7,14 & - & 0 \\
\hline IVG & 0,99 & 0,21 & 0,49 & 0,09 & 0,02 & 0,10 & - & 0 \\
\hline
\end{tabular}

- = tratamiento no aplicado, $0=$ sin germinación

pletamente con plástico negro grueso.

El primer ensayo se instaló el 21 de marzo de 2000; las semillas tenían 3,5 meses (106 días) de almacenamiento a temperatura ambiente. Se evaluaron los tratamientos 1, 2, 4-8 con dos repeticiones cada uno. La evaluación de la germinación fue durante $110 \mathrm{~d}$.

El segundo ensayo se instaló el 08 de agosto de 2000 , las semillas tenían 8,2 meses (246 días) de almacenamiento y se evaluaron los tratamientos 1 a 6 y 8 ; con cuatro repeticiones para los tratamientos sin estratificación (tratamientos 1 y 6) y con dos repeticiones para las estratificadas (tratamientos 2-5, 8). La evaluación de la germinación fue durante 64 d, tiempo que se consideró suficiente.

En el caso de los tratamientos que requerían estratificación, esto se realizó a partir de la fecha de instalación de los ensayos de germinación, retirándose a los 30 ó 60 d según correspondía el tratamiento, momento a partir del cual se evaluó la germinación y se considera días después del tratamiento (ddt).

Las observaciones para los tratamientos bajo iluminación eran diarias y se registraban toda vez que se encontraban semillas germinadas, mientras que para los tratamientos de oscuridad era mensual para el primer ensayo y cada $15 \mathrm{~d}$ para el segundo.

En el primer ensayo se tuvo que descartar semillas para verificar el estado de embrión dada la demora de su germinación, una placa a los 21 ddt del tratamiento 1 y otra a los 10 ddt del tratamiento 7 (todas sin germinación). Asimismo en el segundo ensayo se perdieron a los 60 días de estratificación, una placa del tratamiento 4 y otra del tratamiento 5 .

\section{RESULTADOS}

\section{Efecto del factor luz}

Se pudo observar que la germinación de semillas de $P$. raimondii es afectada positivamente por la luz, ya que bajo iluminación se tiene la mayor germinación sea que se trate de semillas estratificadas o no (ver Figs. 1 y 2). Por ejemplo, para el segundo ensayo, en el tratamiento sin estratificación, bajo luz se obtiene $41 \%$ frente a un 7,1 bajo oscuridad (ver Tabla 2). 


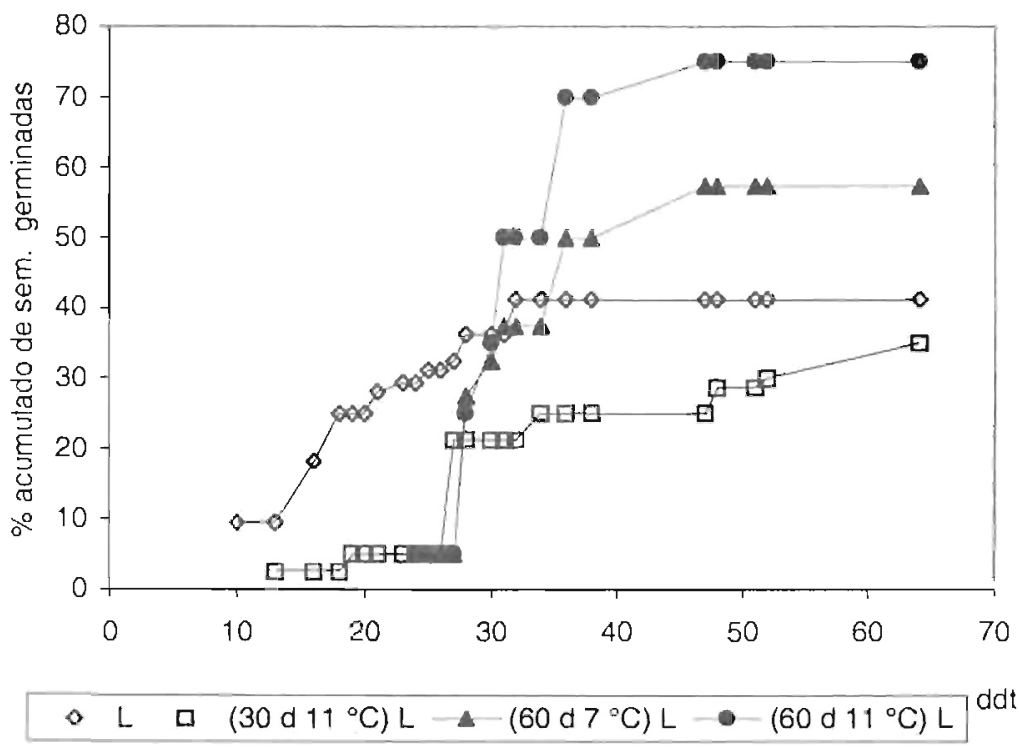

Figura 1. Porcentaje acumulado de germinación de semillas de $P$. raimondii por dias después del tratmiento (ddt) en el primer ensayo, sin y con estratificación a 7 u $11^{\circ} \mathrm{C}$ durante 30 ó 60 dias y evaluadas en luz $\left(\mathrm{L},\left(30 \mathrm{~d} 7^{\circ} \mathrm{C}\right) \mathrm{L},\left(60 \mathrm{~d} 7^{\circ} \mathrm{C}\right) \mathrm{L},\left(60 \mathrm{~d} 11^{\circ} \mathrm{C}\right) \mathrm{L}\right)$ y uscuridad $\left(\mathrm{O},\left(30 \mathrm{~d} 7^{\circ} \mathrm{C}\right) \mathrm{O}\right.$, $\left.\left(30 \mathrm{~d} 11^{\circ} \mathrm{C}\right) \mathrm{O}\right)$.

El hecho de que el valor más alto de germinación obtenido no se aproxime al $100 \%$ puede deberse a que la temperatura que se usó para la germinación $\left(20-25^{\circ} \mathrm{C}\right)$ no sua la óptima y/o, que el alto contenido de humedad de la semilla durante el almacenamiento $(10,1 \%$ en el segundo experimento) haya deteriorado la semilla (Pallais y Falcón, 1991).

\section{Efecto de la temperatura y período de estratificación}

El primer ensayo de estratificación brindó mayor porcentaje de germinación e índice de velocidad de germinación (IVG) siendo el período de 60 días mejor que 30 días y $11^{\circ} \mathrm{C}$ mejor que $7^{\circ} \mathrm{C}$. Sin embargo, en e! segundo ensayo las semillas que no fueron estratificadas brindaron al tos valores de porcentaje de germinación aunque no alcanzaron el valor obtenido en las semillas estratificadas del primer ensayo (ver Fig. 3). Estos resultados muestran que las semillas evaluadas tienen necesidad ya sea de estratificación (en semillas con pocos meses de almacknamiento) o de varios mests de almacenamiento pero no los dos a la vez para que las semillas alcancen el estado físiológico adecuado. $Y$ este último aventaja al primero en acelerar el inicio de la germinación siendo a los 24 días para el primer ensayo frente a los 10 días para el iegundo mostrando diferencias en el grado de madurez de las semillas.

\section{DISCUSIÓN}

De los resultados presentados en este trabajo se puede señalas que $P$. rumondii es una Bromeliácea que requiere luz para que sus semillas germinen. En los dos ensayos, el someter las semillas a iluminación brinda altos valores de germinación (25 y $41 \%$ de germinación y 0,26 y 0,99 de IVG en el primer y segundo ensayo respectivamente para el tratamiento 1). Aún queda por determinar si la germinación observada en oscuridad, aunque baja, se debe a la necesidad de un mejor control de la iluminación en el momento de la evaluación de las semillas. Esto podría ser importante, ya que se conoce que Billbergia elegans (Bromeliaceae) requiere 


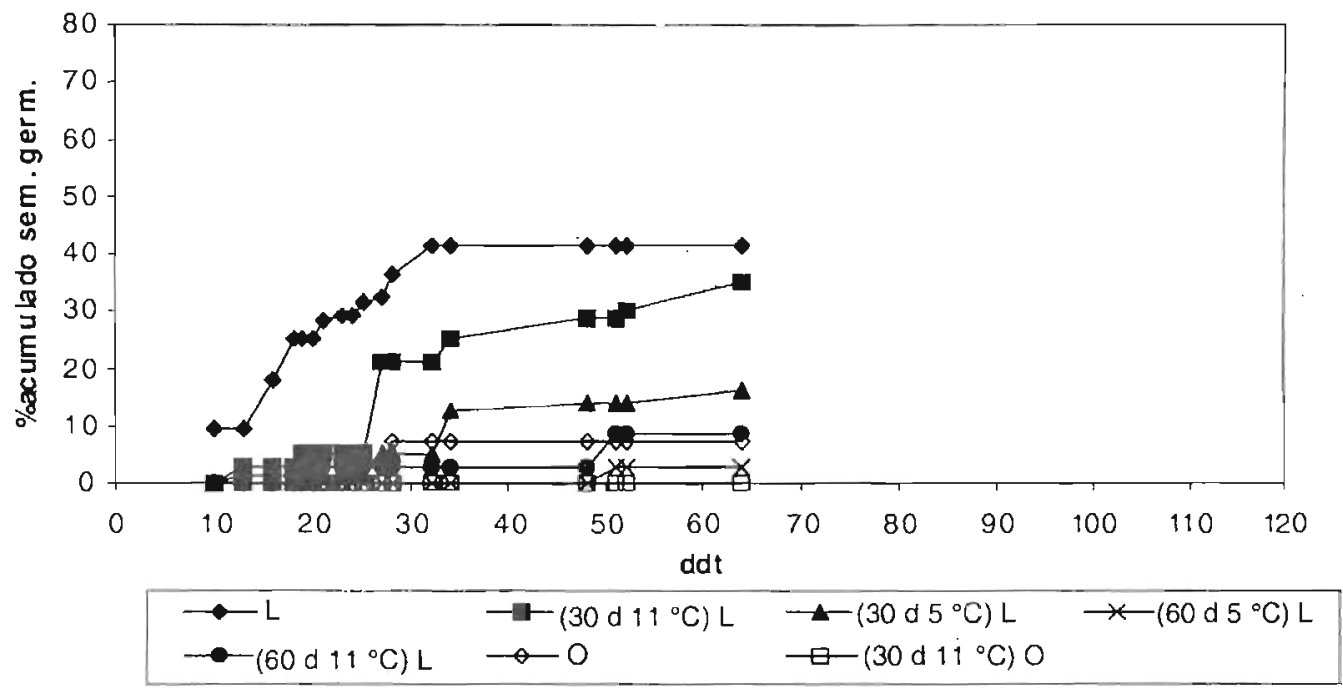

Figura 2. Porcentaje acumulado de germinación de semillas de $P$. raimondii por dias despues del tratamiento (ddt) en el segundo ensayo sin y con estratificación a 7 u $11^{\circ} \mathrm{C}$ por 30 ó 60 días y evaluadas en luz $\left(\mathrm{L},\left(30 \mathrm{~d} 11^{\circ} \mathrm{C}\right) \mathrm{L},\left(30 \mathrm{~d} 5^{\circ} \mathrm{C}\right) \mathrm{L},\left(60 \mathrm{~d} 5^{\circ} \mathrm{C}\right) \mathrm{L},\left(60 \mathrm{~d} 11^{\circ} \mathrm{C}\right) \mathrm{L}\right)$ y oscuridad $(\mathrm{O}$, $\left.\left(30 \mathrm{~d} 11^{\circ} \mathrm{C}\right) \mathrm{O}\right)$.

sólo una breve exposición a la luz para afectar el sistema de fitocromo de tal manera que induce su germinación (Smith y Downs, 1974). Pero este requerimiento de luz para la germinación podría estar reduciendo el éxito del establecimiento de $P$. raimondii en condiciones de baja intensidad luminosa o en ausencia de luz y por lo tanto la ocupación de los hábitat que se encuentren recubiertos con piedras y acúmulo de hojas (Mercier y

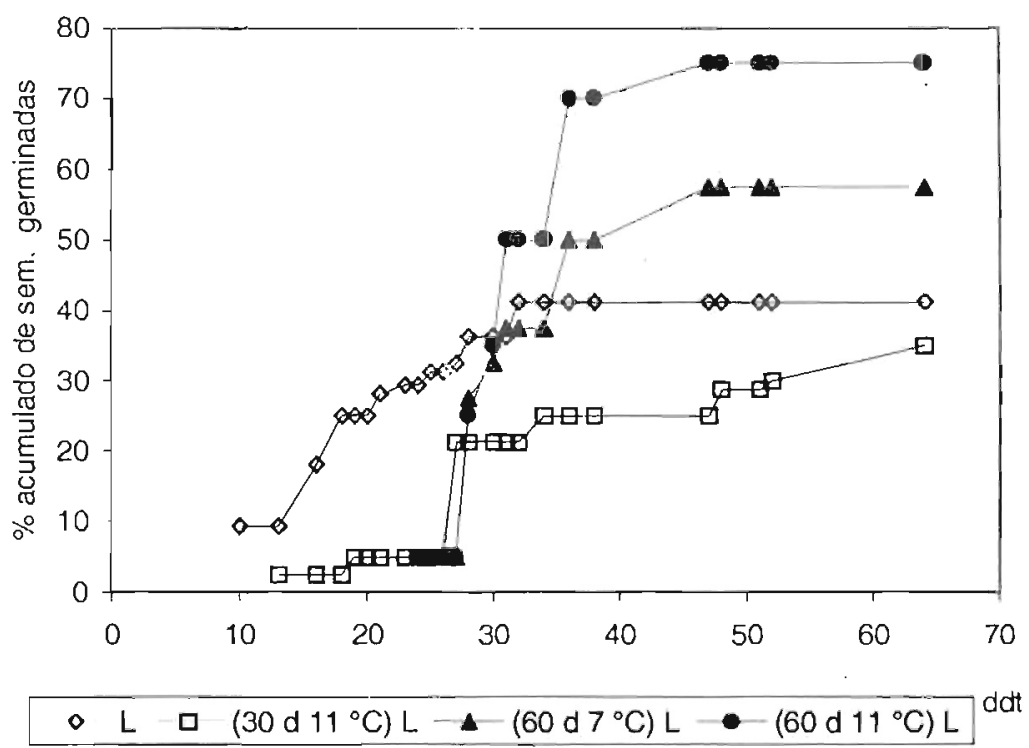

Figura 3. Efecto del almacenamiento, por tres meses (primer ensayo, $\left(60 \mathrm{~d} 7^{\circ} \mathrm{C}\right) \mathrm{L}$ y $(60 \mathrm{~d} 11$ $\left.{ }^{\circ} \mathrm{C}\right) \mathrm{L}$ ) y por ocho meses (segundo ensayo, L, (30d $\left.11^{\circ} \mathrm{C}\right) \mathrm{L}$ ) sin o en interacción con estratificación por 30 días y 60 dias a 7 y $11^{\circ} \mathrm{C}$ sobre los valores de semillas germinadas. 


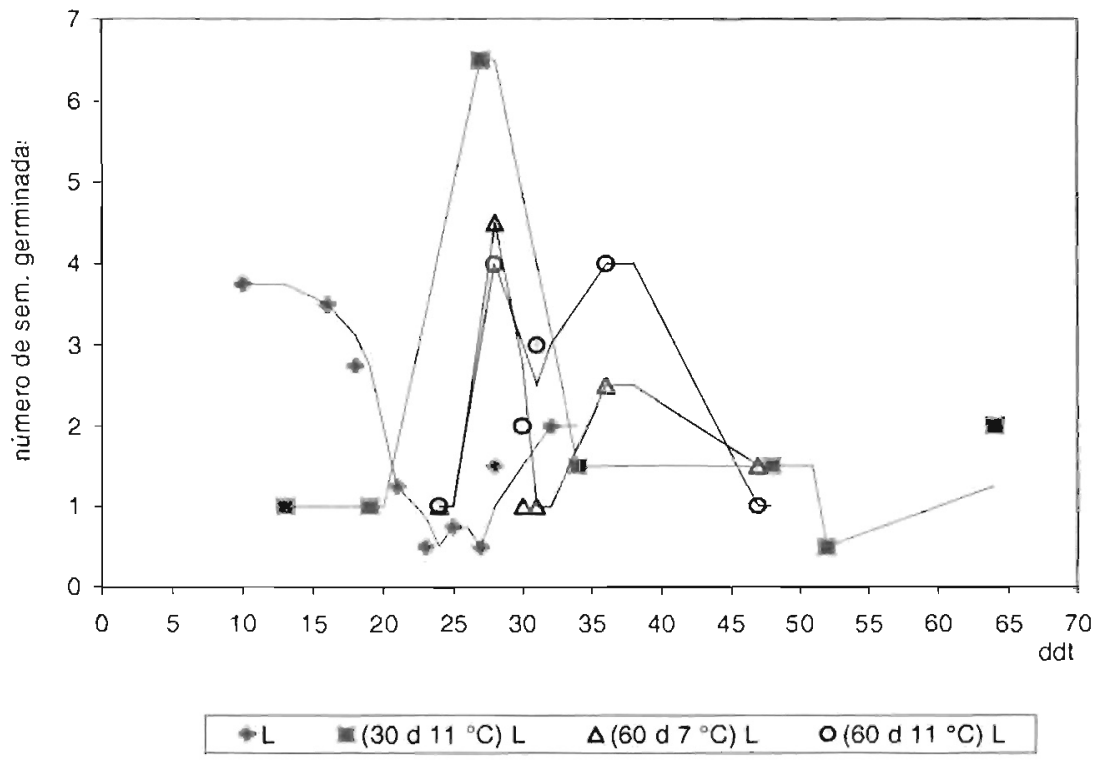

Figura 4. Comparación de líneas de tendencia del curso de la germinación en los tratamientos con los valores más altos obtenidos en el primer $\left(\left(60 \mathrm{~d} 7{ }^{\circ} \mathrm{C}\right) \mathrm{L}\right.$ y $\left.\left(60 d 11^{\circ} \mathrm{C}\right) \mathrm{L}\right)$ y segundo ensayo ( L y $\left.\left(30 \mathrm{~d} 11^{\circ} \mathrm{C}\right) \mathrm{L}\right)$.

Guerreiro, 1990).

$\mathrm{Al}$ parecer las semillas con mayor tiempo de almacenamiento en el laboratorio $(8,2$ meses) aceleran su maduración (este es el caso del segundo ensayo) anulando o haciendo innecesario que se las someta a bajas temperaturas (estratificar) donde $11^{\circ} \mathrm{C}$ era mejor que $7{ }^{\circ} \mathrm{C}$ (primer ensayo). Ambas condiciones (mayor tiempo de almacenamiento y estratificación) resultaron en mejores valores de porcentaje de germinación e IVC aunque la estratificación es la que brinda el mejor porcentaje de germinación (ver figura 3), pero con un inicio y período de la germinación tardío (figura 4). Todo esto estaría indicando una disminución de la viabilidad de las semillas por efecto de las condiciones de almacenamiento. El hecho de que la maduración de las semillas mejore los niveles de germinación podría ser una de las razones que explique la divergencia de resultados en los reportes para P. raimondii que señalan que sus semillas germinan a Jos 32 días (Rivera, 1985); mientras que otros señalan que germinan a los 16 días
(De la Cruz, 1998). Se trataría de semillas con diferente estado de maduración. Además, considerando que el poder germinativo de la semilla está en función de su contenido de humedad y la temperatura de almacenamiento (Roberts, 1972; Pallais, 1991). Entonces, para que este poder dure años ambos requerimientos deben ser adecuados. Así cuando Hartmann (1931) indica que las semillas mantienen seis meses su poder germinativo, mientras que Rivera (1985) menciona que la mantiene años, estarían señalando indirectamente que las semillas que evaluó tenían diferentes condiciones de almacenamiento.

Smith y Downs (1974) hacen notar el rol importante que cumple la temperatura en la germinación de Puya. Así, en el caso de $P$. berteroniana, una especie que se encuentra en altas altitudes, tiene un buen porcentaje de germinación a los $15^{\circ} \mathrm{C}$ y va disminuyendo a medida que la temperatura aumenta hasta los $25^{\circ} \mathrm{C}$. Esto posiblemente suceda también con $P$. raimondii y por lo tanto explique por qué nuestros valores máximos sean menores al 
$100 \%$ ya que se evaluó a temperaturas superiores $\left(20-25^{\circ} \mathrm{C}\right)$.

Se puede señalar que el poder germinativo de las semillas de $P$. raimondii puede manejarse con el mejor conocimiento de las condiciones de la semilla en cuanto a su contenido de humedad, dormancia, temperatura de germinación y manejo de las condiciones de almacenamiento.

\section{AGRADECIMIENTOS}

Agradecemos a National Geographic Society, a través del proyecto "Plant Diversity and endemism in Peru's central highlands" (Grant 6407-99) y al Fondo de Desarrollo Universitario (FEDU) de la Universidad Nacional Mayor de San Marcos (Código del Estudio 001001021) por el financiamiento del presente trabajo. Asimismo expresamos nuestro reconocimiento a Blanca León y Kenneth. R. Young por la revisión del manuscrito y nuestro agradecimiento a María I. La Torre, Ángel Ramírez y Luzmila Cano por su valiosa colaboración en la realización del trabajo.

\section{LITERATURA CITADA}

Cano, A.; M. La Torre y A. Ramírez. 2000. Aspectos cuantitativos sobre la biología de la Puya raimondii Harms (Bromeliaceae). Resúmenes del VIII Congreso Nacional de Botánica. Abril 24-28, 2000. Arequipa, Perú, p. 12.

De la Cruz, J. 2000. Estudio de la densidad poblacional e importancia económica de Puya raimondii Harms Ayacucho- 1998. Resumen del VIII Congreso Nacional de Botánica. p. 57.

Hartmann, O. 1981. Puya raimondii cada vez son menos. Boletín de Lima, N. ${ }^{\circ}$ 10:79

Mackay, 1972. The measurement of viability, pp 172208. En: E. H. Roberts (Editor). Viability of seeds. Syracuse University Press.

Mercier, H. e O. Guerreiro. 1990. Propagação sexuada de algumas bromélias nativas da mata atlántica: efeito da luz e da temperatura na germinação. Hoechnea 17(2): 19-26.

Pallais, N. 1991. Effects of temperature and seed moisture content during storage of true potato seed. American Potato Journal 68(9): 627.

Pallais, N. y R. Falcón. 1991. Importancia del contenido de bumedad de la semilla sexual de papa para su almacenamiento en paises tropicales. En: ALAP. Programa y Compendios. $15 \mathrm{Re}$ unión de ALAP. Lima (Perú). 8-14 setiembre 1991, p. 102.

Rivera, C. A. 1985. Puya raimondii Harms. Boletín de Lima. Vol. Il, N. ${ }^{\circ} 38$, pp 85-91.

Roberts, E. H. 1972. Storage environment and the control of viability, pp. 14-58. E. H. Roberts (editor). Viability of seeds. Syracuse University Press.

Smith L. B. y R. J. Downs. 1974. Flora Neotrópica. Monograph N. 14 (Pitcairnioideae, Bromeliaceae). 